\title{
Risk Analysis of Risk Factors for Pressure Injury Related to Tracheal Intubation in ICU Patients
}

\author{
Yun Shi \\ People's Hospital of Jingjiang City, Jingjiang 214500, Jiangsu Province, China
}

\begin{abstract}
[Abstract] Objective: This article mainly analyzes the risk factors of pressure injury related to tracheal intubation in ICU patients. Methods: This time, the investigation and research were mainly conducted on 110 patients with tracheal intubation received in the ICU of our hospital from June 2020 to June 2021, and the risk factors for related pressure injuries were analyzed. Results: According to statistics, the incidence rate of patients with tracheal intubation-related pressure injury was $23.63 \%$, of which the lip had the highest incidence; the indwelling time of the tracheal tube, the wetness score, the movement force score, and the frictional shear score in the Braden score of the tracheal intubation These are all risk factors for pressure injury related to tracheal intubation $(\mathrm{P}<0.05)$. Conclusion: ICU patients have a higher incidence of related pressure injuries during tracheal intubation, so it is necessary to strengthen the care of risk factors and take reasonable and effective measures to prevent them.
\end{abstract}

Key words: ICU ward; Tracheal intubation; Related pressure injury; Risk factors

Publication date: May, 2021; Publication online: 31 May, 2021

*Corresponding author: Yun Shi, 32961628@qq.com

Device-related pressure injuries mainly refer to pressure injuries caused by the use of medical devices for diagnosis or treatment. The shape of the damaged part is usually the same as the shape of the medical device. According to relevant statistics, tracheal intubation is a common device that causes related pressure injuries in ICU patients, and it is difficult to detect in time in the clinic, so it cannot be dealt with in the first time, and once the injury occurs, it will increase the severity of the patient. Great suffering will adversely affect the outcome of the disease, and may even cause medical disputes ${ }^{[1]}$. Therefore, it is necessary to understand the causes of related pressure injuries in time, and take effective preventive measures to intervene in time to reduce the incidence of injuries. Based on this, the investigation and analysis of risk factors related to pressure injury in ICU patients during tracheal intubation were carried out this time.

\section{Materials and methods}

\subsection{Basic information}

The subjects of this survey are all 110 patients with tracheal intubation received in the ICU from June 2020 to June 2021 in our hospital. The selection criteria: the patients are all over 18 years old, and the patients and their families are aware of this study and sign the consent form voluntarily. Exclusion criteria: Exclude patients with severe mental illness and related stress injuries. Using questionnaires to calculate the baseline data of patients, 75 male patients and 35 female patients, the age limit is 21-70 years old, the average age is $(54.36 \pm 2.22)$ years; the tracheal tube indwelling time is $1-60$ days, the average $(24.13 \pm 1.25) \mathrm{d}$.

\subsection{Survey method and content}

The study was based on relevant references and was reasonably designed using expert consultation methods. It was conducted based on patient baseline data, tracheal intubation methods, tracheal tube indwelling time, ventilator application, whether the tracheal tube should be used with subglottic suction, and whether preventive measures were taken. Investigate; and use the Braden assessment scale to evaluate the Braden score of patients during tracheal intubation.

Braden scale assessment content mainly includes feeling, 
humidity, mobility, mobility, nutrition and friction shear force, etc. The total score is 23 points. The lower the score, the higher the risk of related pressure injury ${ }^{[2]}$.

\subsection{Statistical analysis}

Use SPSS23.0 to process and analyze the data. X2 test is used for counting data, which is described as a percentage; the measurement data is given t-test, which is described as $( \pm \mathrm{s})$; whether the occurrence of tracheal intubation-related pressure injury is regarded as the dependent variable, and there is statistics Differential factors are regarded as independent variables, and through logistic regression analysis, if $\mathrm{P}<0.05$, it means that the difference is statistically significant ${ }^{[3]}$.

\section{Results}

\subsection{Occurrence of pressure injury related to tracheal intubation}

Among the 110 patients in this investigation, 26 patients suffered from tracheal intubation-related pressure injury, of which 19 cases occurred in the lip area, 3 cases occurred in the cheek area, and 2 cases occurred in the oropharynx area., Occurred in 1 case in the auricle and 1 case in the wing of the nose, with a total incidence of $23.63 \%$.

\subsection{Analysis of factors causing pressure injury related to tracheal intubation}

As shown in the data statistics in Table 1, there are differences in the occurrence of pressure injuries related to tracheal tube indwelling time, whether with subglottic suction, tube fixation method, and type of fixator, $\mathrm{P}<0.05$; while on the Braden score, sensory, mobility and There was no significant difference in the nutritional scores, $\mathrm{P}>0.05$; the scores of moisture, mobility, and friction/shear force were statistically significant $(\mathrm{P}<0.05)$.

Table 1. Statistical evaluation of patient treatment effect (n/\%)

\begin{tabular}{|c|c|c|c|c|c|}
\hline \multirow[t]{2}{*}{ Item } & & \multicolumn{2}{|c|}{$\begin{array}{c}\text { Pressure injury related to tracheal } \\
\text { intubation occurred } X 2 / \mathrm{t} P \\
\end{array}$} & \multirow[t]{2}{*}{$\mathrm{X} 2 / \mathrm{t}$} & \multirow[t]{2}{*}{$\mathbf{P}$} \\
\hline & & Yes $(n=26)$ & No $(n=84)$ & & \\
\hline Tracheal tube indwelling time & & $11.21 \pm 11.14$ & $6.25 \pm 4.13$ & 3.4170 & $<0.05$ \\
\hline \multirow[t]{2}{*}{ Breathing method } & Spontaneous breathing & 1 & 6 & \multirow{2}{*}{2.4814} & \multirow{2}{*}{$>0.05$} \\
\hline & Mechanical ventilation & 25 & 78 & & \\
\hline \multirow{2}{*}{ Tracheal intubation method } & Oral & 24 & 79 & \multirow{2}{*}{2.5712} & \multirow{2}{*}{$>0.05$} \\
\hline & Nasal & 2 & 5 & & \\
\hline \multirow{2}{*}{$\begin{array}{l}\text { Vocal cord suction under the } \\
\text { door }\end{array}$} & Yes & 17 & 31 & \multirow{2}{*}{4.0813} & \multirow{2}{*}{$<0.05$} \\
\hline & No & 9 & 53 & & \\
\hline \multirow{2}{*}{ Tracheal tube material } & PVC & 23 & 60 & \multirow{2}{*}{1.9354} & \multirow{2}{*}{$>0.05$} \\
\hline & Other & 3 & 24 & & \\
\hline \multirow{5}{*}{ Preventive measures } & Foam dressing & 1 & 1 & \multirow{5}{*}{3.1035} & \multirow{5}{*}{$>0.05$} \\
\hline & Artificial leather & 4 & 3 & & \\
\hline & hydrocolloid & 3 & 3 & & \\
\hline & Transparent dressing & 1 & 0 & & \\
\hline & None & 17 & 77 & & \\
\hline \multirow{3}{*}{ Type of fixator } & Ordinary syringe & 5 & 51 & \multirow{3}{*}{4.5231} & \multirow{3}{*}{$<0.05$} \\
\hline & Disposable fixator & 2 & 14 & & \\
\hline & Disposable dental pad & 19 & 19 & & \\
\hline \multirow{6}{*}{ Braden score during intubation } & Feeling & $1.98 \pm 0.75$ & $2.14 \pm 1.03$ & 0.7332 & 0.4650 \\
\hline & Humidity & $3.55 \pm 0.45$ & $3.21 \pm 0.62$ & 2.5895 & 0.0109 \\
\hline & Activity & $1.15 \pm 0.21$ & $1.13 \pm 0.21$ & 0.4244 & 0.6721 \\
\hline & Movement force & $1.34 \pm 0.64$ & $1.75 \pm 0.83$ & 2.3123 & 0.0227 \\
\hline & Nutrition & $1.84 \pm 0.49$ & $1.91 \pm 0.62$ & 0.5265 & 0.5996 \\
\hline & Friction/shear force & $1.61 \pm 0.49$ & $1.85 \pm 0.43$ & 2.4053 & 0.0179 \\
\hline
\end{tabular}




\subsection{Regression analysis of high-risk factors}

After regression analysis, it is concluded that tracheal tube indwelling time, subglottic suction, type of fixator, Braden wetness during intubation, movement force, friction force/shear force score are all considered as high risk factors for tracheal intubation-related pressure injury is relevant (Table 2).

Table 2. Logistic regression analysis of high-risk factors

\begin{tabular}{|c|c|c|c|c|}
\hline \multirow{2}{*}{ Item } & \multirow{2}{*}{ OR } & \multicolumn{2}{|c|}{$95 \% \mathrm{CI}$} & \multirow{2}{*}{$\mathrm{P}$} \\
\hline & & Lower limit & Upper limit & \\
\hline Tracheal tube indwelling time & 0.92 & 0.87 & 0.97 & 0.0131 \\
\hline Subglottic attraction & 1.39 & 1.09 & 1.79 & 0.0051 \\
\hline Fixer type & 0.75 & 0.42 & 1.37 & 0.0324 \\
\hline Moisture score during intubation & 0.32 & 0.14 & 0.72 & 0.0060 \\
\hline Mobility score during intubation & 2.05 & 1.10 & 3.95 & 0.0310 \\
\hline $\begin{array}{l}\text { Friction/shear force score during } \\
\text { intubation }\end{array}$ & 2.64 & 1.11 & 6.50 & 0.0340 \\
\hline
\end{tabular}

\section{Discussion}

In this research investigation, ICU patients have a higher incidence of related pressure injuries during tracheal intubation, and the lips are the most frequent site. Therefore, in clinical monitoring, it is necessary to pay close attention to the patient's skin condition and pay attention to the fixation device. Control the tightness of the fixation device for the parts that are in contact with the tracheal tube and the skin to prevent pressure injuries ${ }^{[4]}$.

An investigation of ICU patients found that the indwelling time of the tracheal tube is a high-risk factor caused by related pressure injuries. According to clinical application norms, the indwelling time of the tracheal tube is usually not more than 2-3 weeks. Once the indwelling time is too long, it may be Cause the patient's lungs to be infected, and complicated by throat damage ${ }^{[5]}$. Therefore, in daily monitoring, it is necessary to evaluate the patient's condition, improve the patient's spontaneous breathing ability, and prompt the patient to extubate the tube as soon as possible, thereby reducing the occurrence of tracheal intubation-related pressure injuries.

The subglottic suction tracheal tube is also a high risk factor. According to the relevant guidelines, the reasonable application of the subglottic secretion drainage device tracheal tube can prevent ventilator-related pneumonia to a certain extent. However, for the same type of tracheal tube, because the tube The cavity is relatively thick, so it will cause greater pressure on the local skin and mucosa, which is very easy to cause damage. Therefore, it is necessary to avoid this situation reasonably to prevent pressure injury from occurring.

In this research investigation, it was found that the Braden score during intubation, moisture, mobility, friction/shear force, etc. will increase the risk of intubation-related pressure injury. When the moisture score is higher, the risk will be smaller. The main reason is that during the evaluation, the medical staff mainly make the diagnosis by observing the fluid on the patient's skin surface, etc. These factors are extremely easy to be effectively identified by the nursing staff and attract attention, so the medical staff can take effective measures in time, such as changing clothes, Rubbing the body frequently, and keeping the patient's skin dry reasonably, these measures can reduce the occurrence of pressure injury to a certain extent ${ }^{[6-8]}$. As for the movement force, friction force and shear force, etc., during tracheal intubation, if the design is not good or the fixation is too tight, it will cause the vertical pressure to increase, which will cause the oral and nasal mucosa to be damaged. At the same time, the patient is moved. There may be friction between the tube and the skin. Once the tube is fixed incorrectly, it will generate a large vertical pressure and shear force, which will eventually cause pressure damage. Therefore, it is necessary to ensure that the tube is fixed when performing tracheal intubation. The tightness is appropriate, and the catheter is moved synchronously during the movement of the patient to effectively reduce the influence of mechanical factors.

In summary, ICU patients with endotracheal intubation-related pressure injury are related to the 
indwelling time of the endotracheal tube, the indwelling endotracheal tube with glottis, the wetness of the Braden score, the movement force and the friction and other factors, which need to be paid more attention and reasonable. Prevent the occurrence of related stress injuries.

\section{References}

[1] Zhang Q, Song CC, Zou Q, et al. Observation on the effect of improved oral endotracheal intubation fixation on ICU patients with instrumental pressure injury of the mouth, face and neck $[\mathrm{J}]$. Chinese General Medicine 2020,18(8): 1421-1424, ISTIC, 2020.

[2] Wu D, Jin Y, Lv XY, Chen SY, Zhang J. Analysis of current status and influencing factors of oxygen therapy device-related pressure injury in ICU patients[J]. Zhejiang Medicine, 2020, v.42(19): 104-106 +110.

[3] Wen W, Lin BL, Chen XF, et al. Study on the correlation between nutrition-related indicators and the risk of stress injury in patients with tropical islands in China[J]. Journal of Nursing of Chinese People's Liberation Army, 2020,037(001):47-50,55.

[4] Cao ZX, Wei YQ, Zhang J, et al. Meta-analysis of the epidemiological characteristics of medical device-related pressure injuries in adult inpatients[J]. Chinese Nursing Management, 2020,20(05):75-84.

[5] Mao S, Li Y, Wang ZX, et al. Effects of Ticagrelor on oxidative stress, coagulation function, platelet function and related factors in patients with coronary artery disease undergoing interventional therapy[J]. Journal of Hainan Medical University (English Edition) , 2019,025(006): 24-27.

[6] Jin TT, Zhou YY, Lou D, et al. Analysis of the current status and influencing factors of ICU nurses' knowledge, belief, practice and influencing factors in the prevention of medical device-related stress injury $[\mathrm{J}]$. Chinese Journal of Modern Nursing, 2020, 26(12): 1606-1610.

[7] Huang QP, Zhang JR, Zheng MC, et al. Application research of ICU medical device-related pressure injury risk assessment scale in critically ill patients[J]. Chinese Journal of Nursing, 2018,053(008):967-970.

[8] Qin LL, Yun WJ, Hang Z. Analysis of risk factors for pressure injury related to tracheal intubation in ICU patients[J]. Journal of Nurses Training 2020, 35(12): 1105-1108, ISTIC, 2020. 